\title{
Evaluation of sweet taste sensitivity in type-II Diabetes Mellitus patients
}

\author{
Naveen Kumar Z1, Gowri Kumari B.N.S
}

1. Assistant Professor, Department of Physiology, Santhiram Medical College, Nandyala, Kurnool, Andhra Pradesh,
India.
2. Assistant Professor, Department of Physiology, Viswabharathi Medical College, Kurnool, Andhra Pradesh, India.

\begin{abstract}
Background: The objective is to evaluate the sweet taste sensitivity among type-II diabetes mellitus patients. The taste influences the food selection of individual, by choosing the food he likes most. Taste sensitivity impairment may lead to ingest greater quantities of substances for the perception of taste, contributing to increased sodium and sugar intake. Methods: This is a cross-sectional study consisted of 227 subjects (127 type-II Diabetic patients \& 100 non-diabetic individuals) of both the genders and age-matched. Sweet taste sensitivity tests were done using different concentrations of glucose solution and compared among the diabetic patients with FBS more than $18 \mathrm{omg} / \mathrm{dl}$ and diabetic patients with FBS less than $180 \mathrm{mg} / \mathrm{dl}$ and also compared among the diabetic patients and non-diabetic individuals. The final concentration at which the patient was able to perceive the taste was recorded. Statistical analysis was done using Student's unpaired T-test. $P$ ᄀvalues of $<0.05$ were considered to be statistically significant. Results: The mean of sweet taste sensitivity among diabetic patients with FBS $>180 \mathrm{mg} / \mathrm{dl}$ was $6245 \mathrm{mg} / \mathrm{l}$ and the mean of sweet taste sensitivity in the diabetic patients with FBS $<180 \mathrm{mg} / \mathrm{dl}$ was $2249 \mathrm{mg} / \mathrm{l}$ with $\mathrm{P}<0.001$ which is significant. The mean of sweet taste sensitivity among diabetic patients with FBS $>180 \mathrm{mg} / \mathrm{dl}$ was $6245 \mathrm{mg} / \mathrm{l}$, and the mean of sweet taste sensitivity in the non-diabetic individuals was $1979 \mathrm{mg} / \mathrm{l}$ with $\mathrm{P}<0.01$ which is significant. The mean of sweet taste sensitivity among diabetic patients with FBS $<180 \mathrm{mg} / \mathrm{dl}$ was $2249 \mathrm{mg} / \mathrm{l}$, and the mean of sweet taste sensitivity in the non-diabetic individuals was $1979 \mathrm{mg} / \mathrm{l}$ with $\mathrm{P}>0.05$ which is not significant. Conclusion: Type-II Diabetes Mellitus patients have lesser sensitivity for the sweet taste. Loss of sensitivity leads to the increase in sugar consumption being the risk factor for worsening the disease.
\end{abstract}

KEYWORDS: Diabetes Mellitus type-II; Sweet taste; Taste threshold; Fasting blood glucose

\section{INTRODUCTION}

$\mathrm{T}$ The food choices of people are changed as people are preferring food which gives pleasure than the foods having nutrient value [1]. Taste perception and food preferences are the main factors which decide dietary practices [2] leading to the occurrence of noncommunicable diseases [3].

The taste sensation is experienced when the chemical concentration of a tasting reaches a threshold level which activates taste receptors $\&$ generates action potentials in gustatory nerve fibers and gives taste perception [4]. Impairment of taste sensation was reported long before in patients with diabetes mellitus (DM) [5,6], and the impairment is found to be mostly for the sweet sensation compared to other taste modalities $[7,8]$.

Since it is also observed that patients with T2DM crave for high carbohydrate-containing foods [9], these patients likely consume more sugar compared to non-diabetics. The taste plays an essential role in the peoples security and quality of life, as the loss or impairment of gustatory function may cause the risk of food poisoning after eating spoiled food [10]. Also, the

Correspondence: Gowri Kumari, Assistant Professor, Department of Physiology, Viswabharathi Medical College, Kurnool, Andhra Pradesh. EMail: gowrikumari342@gmail.com

\begin{tabular}{|l}
$\mid$ \\
eISSN: 2395-0471
\end{tabular}


taste influence the food selection of individual, by choosing the food he likes most [11]. Taste sensitivity impairment may lead to ingest greater quantities of substances for the perception of taste, contributing to increased sodium and sugar intake. The increased intake of these nutrients can contribute to the progression of the diseases such as hypertension and diabetes mellitus type [12]

The present study is done to evaluate the sensitivity of sweet taste among type-II Diabetic Mellitus patients.

\section{Material And Methodology}

Type of study: Cross-sectional study

Ethical clearance: Ethical clearance was obtained from the institutional ethical committee, and written informed consent form was obtained from all the participants.

Study site: Santhiram General Hospital,
Nandyala

Sample size \& sampling method: A convenience sample and sample size is 227 .

\section{Study population:}

Inclusion criteria: The test group had 127 patients both male and female, diagnosed with type-II Diabetes Mellitus further separated into 2 groups: Test group-I diabetic patients with blood glucose more than $180 \mathrm{mg} / \mathrm{dl}$ and Test group-II diabetic patients with blood glucose less than $180 \mathrm{mg} / \mathrm{dl}$. Control group had 100 non-diabetic individuals, both male and female, employees of Santhiram general hospital. Aged between 30 to 70 years with above inclusion criteria were included in the study.

Exclusion criteria: People with complications of the oral cavity, alcoholics, smokers, people with age more than 70 years, individuals suffering from cold/flu, or with something that could influence the perception of taste were excluded.

Collection of sample: After overnight fasting, three $\mathrm{ml}$ of blood from all the participants was drawn to an EDTA tube and estimated FBS.

Sweet taste sensitivity test: The substance used for sweet taste was glucose. Mole is the gram-molecular weight of a substance. Thus 1 mol of glucose is $180 \mathrm{gms}$ and $1 \mathrm{mmol}=180 \mathrm{mg}$. Thus, on dissolving $180 \mathrm{~g}$ of glucose in a final volume of 1litre, to get a1M/L glucose solution. From that stock solutions serial dilutions of 1 in 2,1 in 4,1 in 8,1 in 16,1 in 32,1 in 64, 1 in 128 and 1 in 256 were Prepared with concentration $90 \mathrm{gm} / 1, \quad 45 \mathrm{gm} / 1, \quad 22.5 \mathrm{gm} / 1$, $11.25 \mathrm{gm} / 1, \quad 5625 \mathrm{mg} / 1,2812 \mathrm{mg} / 1, \quad 1406 \mathrm{mg} / 1$, $703 \mathrm{mg} / 1$. Solutions were stored at $4^{0} \mathrm{c}$ in coded airtight $100 \mathrm{ml}$ plastic container, each having separate pipette dropper.

Whole mouth stimulation method is used for the sensitivity of tests. The sensitivity test was done to determine the threshold index detection for sweet taste at which participant perceive the taste. The samples were given to the subjects in disposable cups with a volume of $30 \mathrm{ml}$. To test the taste sensitivity, solutions from lower concentration to higher concentration were given in disposable cups and asked to taste the solution. After tasting each serial dilution, they were asked to rinse the mouth with water to clean the taste buds. Whenever they recognized the sweet taste, the reading is noted

Statistical analysis: All the results were analyzed statistically using MS Excel. The unpaired t-test was used to compare the threshold for the sweet taste of the control group and the study group. $\mathrm{P}$-value less than 0.05 was taken as significant.

\section{Results}

The Mean age of male diabetic subjects is 48 years. Mean age of female diabetic subjects is 44 years. The Mean age of males in the non-diabetic group is 48 years, while the age of female nondiabetic subjects is 45 years. This reflects agematched and sex-matched subjects in diabetics and non-diabetics control group. Total number of type-II Diabetic patients 127 , among this FBs levels $>180$ were 29 and $<180$ were 98 .

\section{Table 1. Comparison of taste sensitivity for} sweet

\begin{tabular}{|c|c|c|c|c|}
\hline \multirow{2}{*}{ parameter } & \multicolumn{3}{|l|}{ Blood glucose levels $(\mathrm{mg} / \mathrm{dl})$} & P-value \\
\cline { 2 - 5 } & Control & $<180$ & $>180$ & \\
& $(\mathrm{n}=100)$ & $(\mathrm{n}=98)$ & $(\mathrm{n}=29)$ & \\
\hline Taste & 1979 & 2249 & $6245 \pm$ & $>0.05^{*}$ \\
sensitivity & \pm 155 & \pm 153 & 504 & $<0.001 \$$ \\
for sweet & & & & $<0.01 \#$ \\
\hline
\end{tabular}

*Comparison between control and glucose level $<180 \mathrm{mg} / \mathrm{dl}$, Non-significant.

\$Comparison between glucose level <180mg/dl and $>180 \mathrm{mg} / \mathrm{dl}$ (Extreme significant).

\#Comparison between control and glucose level $>180 \mathrm{mg} / \mathrm{dl}$ (Very significant).

\section{Discussion}

Taste sensitivity for sweet is found to be more reduced in those people with diabetes whose Fasting blood sugar is more than $180 \mathrm{mg} / \mathrm{dl}$ compared to people with diabetes whose Fasting blood sugar is less than $180 \mathrm{mg} / \mathrm{dl}$ which is significant. Taste sensitivity for sweet is found to be decreased in diabetic subjects whose FBS is more than $180 \mathrm{mg} / 1$ compared to non-diabetic subjects which are significant. Thus, the results showed a decreased sensitivity to sweet taste in diabetic patients compared to non-diabetic 
individuals. The reduction of sensitivity to sweet taste can contribute to an increase in the intake of refined carbohydrates because this dysfunction may lead to higher consumption of sugar [13]. This fact is a risk factor for diabetes because high consumption of sugar causes increased glucose level in blood. Type 2 Diabetes Mellitus individuals with loss of taste perception have hyposalivation, xerostomia and low production of taste protein. And also, the deficiency or absence of taste interferes in salivation and maturation of the taste buds, thereby causing changes in the perception of taste [12].

Yu $J$ et al. in their study showed that people with diabetes tend to take rich carbohydrate foods, more often when they have less glycemic control [14]. Rahul S. Khobragade et al. in their study confirms a significant increase in taste threshold for sweet $(\mathrm{P}<0.0001)$, salt, sour and bitter $(\mathrm{P}<0.001)$ in type 1 diabetic [15]. Shahnaz Mohammad et al. in their study found that lower sensitivity to sweet taste may lead to an increased preference for glucose in diabetic patients [16].

\section{Conclusion}

As Diabetic patients have lower sensitivity to sweet taste compared to non-diabetic individuals, they require higher glucose concentrations to identify the sweetness which leads to consumption of high sugar concentrated food which is a risk factor for progression of the disease.

\section{Conflict of interest : Nil \\ Source of funding : Nil \\ REFERENCES}

1. Lowe M, Butryn M: Hedonic hunger: a new dimension of appetite? Physiol Behav. 2007; 91(4):432-9

2. Drewnowski A, Henderson S, Levine A, Hann C. Taste and food preferences as predictors of dietary practices in young women. Public Health Nutr 1999;2(4):513-9

3. Taylor R, Badcock J, King H, Pargeter K, Zimmet P, Fred T, Lund M, Ringrose H, Bach F, Wang R. Dietary intake, exercise, obesity and non-communicable disease in rural and urban populations of three Pacific Island countries. J Am Coll Nutr. 1992;11(3):28393

4. Gutierrez R, Simon S. Chemosensory processing in the taste - reward pathway. Flavour Frag J. 2011;26(4):231-8

5. Chochinov R, Ullyot G, Moorhouse J: Sensory perception thresholds in patients with juvenile diabetes and their close relatives. $\mathrm{N}$ Engl J Med 1972;286(23):1233-7

6. Lawson W, Zeidler A, Rubenstein A: Taste detection and preferences in diabetics and their relatives. Psychosom Med 1979;41(3):219-27

7. Gondivkar SM, Indurkar A, Degwekar S, Bhowate R: Evaluation of gustatory function in patients with diabetes mellitus type 2 . Oral Surg Oral Med Oral Pathol Oral Radiol Endod. 2009;108(6):876-80

8. KhobragadeR, WakodeS, KaleA: Physiological taste threshold in type 1 diabetes mellitus. Indian J Physiol Pharmacol 2012;56(1):42

9. 9. Yu J, Shin M, Kim D, Lee J, Yoon S, Kim S, Koh E, Lee W, Park JY, Kim MS. Enhanced carbohydrate craving in patients with poorly controlled Type 2 diabetes mellitus. Diabet Med 2013;30(9):1080-6

10. Boesveldt S, Lindau ST, McClintock MK, Hummel T, Lundström JN. Gustatory and olfactory dysfunction in older adults: a national probability study. Rhinology. 2011; 49(3):324-30

11. Palheta NFX, Targino MN, Peixoto VS, Alcântara FB, Jesus CC, Araújo DC, et al. Anormalidades sen-soriais: olfato e paladar. Arq Int Otorrinolaringol. 2011;15(3):350-8

12. Negrato CA, Tarzia O. Buccal alterations in diabetes mellitus. Diabetol Metab Syndr. 2010; 15;2:3

13. WasalathanthriS, Hettiarachchi P, Prathapan S. Sweet taste sensitivity in pre-diabetics, diabetics and normoglycemic controls: a comparative cross-sectional study. BMC Endocr Disord [Internet]. 2014;14:67. Available from: http://bmcendocrdisord. biomedcentral.com

14. Yu J, Shin M, Kim D, Lee J, Yoon S, Kim S, Koh E, Lee W, Park JY, Kim MS: Enhanced carbohydrate craving in patients with poorly controlled Type 2 diabetes mellitus. Diabet Med 2013;30(9):1080-6

15. Khobragade RS, Wakode SL, Kale AH. Physiological Taste Threshold in Type 1 Diabetes Mellitus, Indian $\mathrm{J}$ Physiol Pharmacol, Jan-Mar 2012;56(1):42-7

16. Gaphor SM, Saeed RA. The Evaluation of taste threshold for four main tastes between diabetic and healthy individuals. European Scientific Journal. 2014;10(6): 